\title{
Relations among storage, yield, and instream flow
}

\author{
Richard M. Vogel, ${ }^{1}$ Jack Sieber, ${ }^{2}$ Stacey A. Archfield, ${ }^{1}$ Mark P. Smith, ${ }^{3}$ Colin D. Apse, ${ }^{4}$ \\ and Annette Huber-Lee ${ }^{5}$
}

Received 2 June 2006; revised 13 January 2007; accepted 29 January 2007; published 1 May 2007.

[1] An extensive literature documents relations between reservoir storage capacity and water supply yield and the properties of instream flow needed to support downstream aquatic ecosystems. However, the literature that evaluates the impact of reservoir operating rules on instream flow properties is limited to a few site-specific studies, and as a result, few general conclusions can be drawn to date. This study adapts the existing generalized water evaluation and planning model (WEAP) to enable general explorations of relations between reservoir storage, instream flow, and water supply yield for a wide class of reservoirs and operating rules. Generalized relationships among these variables document the types of instream flow policies that when combined with drought management strategies, are likely to provide compromise solutions to the ecological and human negotiations for water for different sized reservoir systems. The concept of a seasonal ecodeficit/ecosurplus is introduced for evaluating the impact of reservoir regulation on ecological flow regimes.

Citation: Vogel, R. M., J. Sieber, S. A. Archfield, M. P. Smith, C. D. Apse, and A. Huber-Lee (2007), Relations among storage, yield, and instream flow, Water Resour. Res., 43, W05403, doi:10.1029/2006WR005226.

\section{Introduction}

[2] It is no longer possible to exploit water resources for human needs without taking into consideration ecological flow needs. After two centuries of dam-building, only $2 \%$ of U.S. rivers remain free flowing [Benke, 1990], which has caused large-scale hydrologic [Graf, 1999] and environmental disruption [Dynesius and Nilsson, 1994] both in the United States and elsewhere [Postel, 1995]. Despite the widespread degradation of its river systems, the United States still has no comprehensive plan to secure the instream flows needed to support the diversity of freshwater life and to sustain ecological functions [Postel and Richter, 2003].

[3] The federal Clean Water Act offers a broad and clear mandate from the U.S. Congress to protect river health because its goal is "to restore and maintain the chemical, physical, and biological integrity of the Nation's waters," Yet federal and state agencies administering this act have focused primarily on the chemical integrity of rivers and on the protection of wetlands through the regulation of dredge and fill activities. They have done little explicitly to regulate the quantity and timing of river flows to protect the physical and biological integrity of rivers [Postel and Richter, 2003]. What effort has been made to regulate water quantity and timing issues in this country has fallen to individual states, either through the authority in the federal Clean Water Act giving states the authority to develop and implement water

\footnotetext{
${ }^{1}$ Department of Civil and Environmental Engineering, Tufts University, Medford, Massachusetts, USA.

${ }^{2}$ Stockholm Environment Institute, Tufts University, Somerville, Massachusetts, USA.

${ }^{3}$ The Nature Conservancy, Boston, Massachusetts, USA.

${ }^{4}$ The Nature Conservancy, New Paltz, New York, USA.

${ }^{5}$ International Food Policy Research Institute, Washington, D. C., USA.
}

Copyright 2007 by the American Geophysical Union. 0043-1397/07/2006WR005226\$09.00 quality standards or through the state's own water allocation or water withdrawal management programs.

[4] The states have tackled the issue of managing the quantity and timing of flows in rivers unevenly at best. We have found no comprehensive guidance that is available to managers of reservoir systems on how to deliver a reliable water supply yield while simultaneously maintaining the downstream aquatic ecosystem. We speculate that one reason for this lack of clear guidance and lack of published literature devoted to methods for balancing human and ecological needs for water is in large part a result of the lack of a robust federal policy and the work and attention such a policy would generate. In fact, much of the most relevant literature in this area now originates in South Africa because they did institute a national water policy. The rich literature now emerging from South Africa results in large part from legislative efforts which began in the mid-1990s to ensure that requirements for both basic human needs and the environment are met before potential future users can be licensed to abstract additional water [Department of Water Affairs and Forestry, 1997].

\section{Impact of Dams on the Ecological Flow Regime}

[5] There is now an extensive literature devoted to a description and evaluation of the general ecological impacts of dams on rivers [see Collier et al., 1996]. There is also recent interest in defining the particular impacts of dams on the downstream hydrologic regime [see, e.g., Magilligan and Nislow, 2005]. Interestingly, few of the studies on this subject to date have accounted for the impact of the operational aspects of the dams such as their storage volume, operating rule, demand schedule, etc., on downstream hydrologic conditions. It is very clear from the theory of reservoir behavior that the impact of reservoirs on downstream hydrologic conditions will depend primarily upon their storage $S / \mu$ 

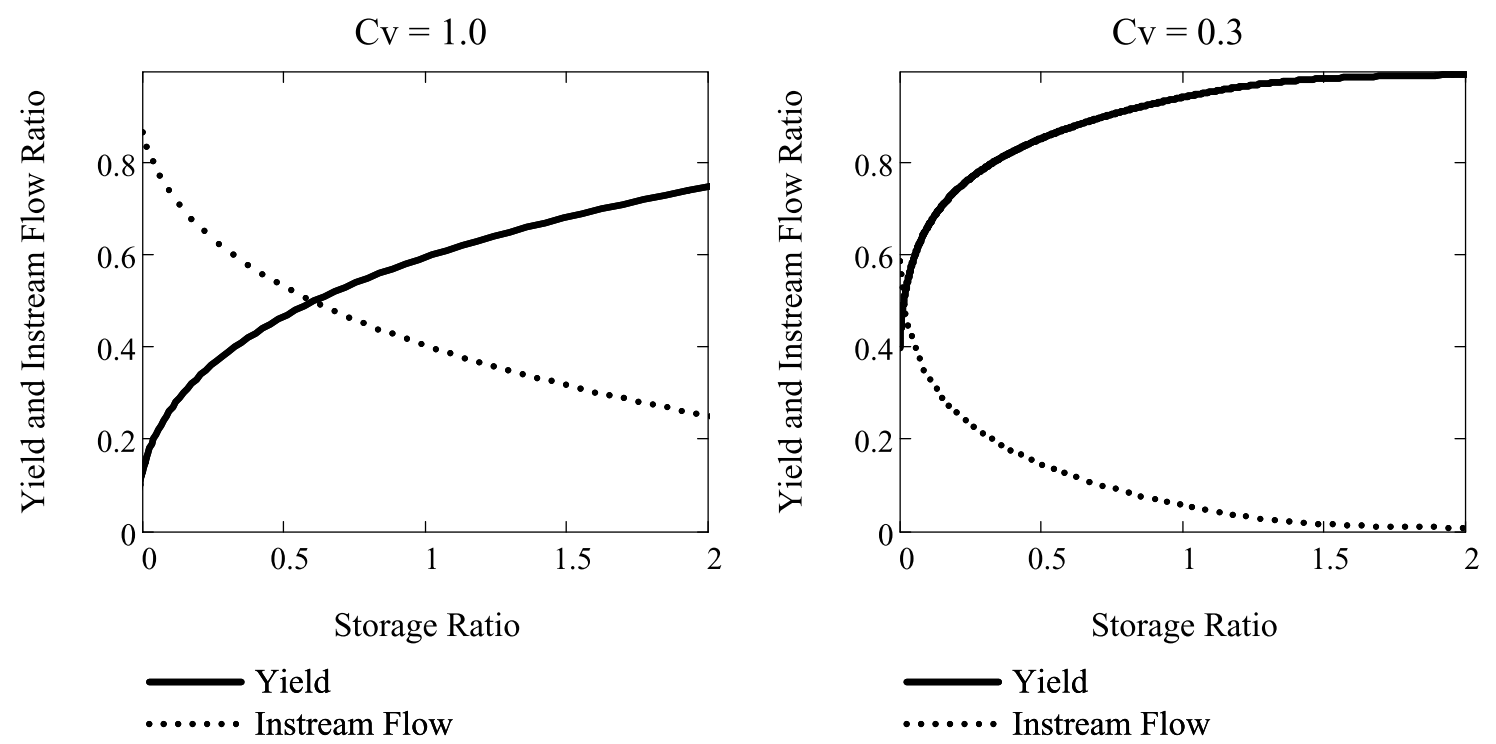

Figure 1. The relationship between the storage ratio $S / \mu$ and both the yield ratio $Y / \mu$ and the instream flow ratio $I / \mu$ for coefficient of variations of annual streamflows $C_{v}=1.0$ and $C_{v}=0.3$.

and yield $Y / \mu$ ratios, where $S, Y$, and $\mu$ are the storage capacity, annual yield, and mean annual inflow, respectively, to the reservoir system [Vogel et al., 1999]. To fully understand the ecologic, geomorphologic, and hydrologic impacts of dams, it is necessary to integrate our knowledge of all factors that influence their operational behavior.

[6] Consider a reservoir system with storage capacity $S$, fed by average annual inflows $\mu$ with two annual average releases, one for water supply $Y$ and the remainder for instream flow $I$. In this study, all releases made from a reservoir to the downstream river, whether they are controlled or uncontrolled spills, are defined as instream flows. Figure 1 illustrates how $I$ and $Y$ vary with $S$ where all three variables are standardized by dividing by $\mu$. When evaporation, seepage, and other losses are ignored, then all water not released as water supply yield $Y$ ends up as instream flow $I$, and hence $\mu=Y+I$, which further implies that the yield ratio and instream flow ratios sum to one so that $(Y / \mu)+(I / \mu)=1$. Figure 1 considers two different values of the coefficient of variation of annual inflows $\mathrm{C}_{\mathrm{v}}=0.3$ and 1.0 , roughly corresponding to temperate and semiarid regions, respectively. Figure 1 illustrates that reservoir systems with small storage ratios lead to much greater values of average annual instream flow than systems with large storage ratios. In general, the instream flow ratio varies inversely with the storage ratio and tends to decrease rapidly as water supply yields increase due to increasing storage ratios. Figure 1 illustrates that it is much more difficult to maintain instream flows for systems with large storage ratios than for systems with small storage ratios. If we consider a constant storage ratio, Figure 1 illustrates that reservoir systems in temperate regions (low $\mathrm{C}_{\mathrm{v}}$ ) will generally have a lower fraction of water available for instream flow (relative to the mean annual flow) than similar systems in arid regions. This is because for a given storage ratio, yields are greater in temperate regions where $\mathrm{C}_{\mathrm{v}}$ is low, than in arid regions where variability is much greater.

[7] Figure 1 is based on the generalized storage-reliabilityyield relations developed by Vogel and Stedinger [1987]. Those relations for AR(1) lognormal annual reservoir inflows provide a good approximation to the overall behavior of thousands of actual reservoir systems in the United States [Vogel et al., 1999]; however, the remainder of this study uses the water evaluation and planning model [Yates et al., 2005a, 2005b] with a daily time step, rather than the annual time step used to construct Figure 1.

[8] The primary goal of this study is to explore the general behavior of water supply reservoirs with a view toward balancing both the human and ecological requirements for water. A second goal is to provide a framework for the evaluation of different types of instream flow policies that lead to the most favorable tradeoffs between ecological and human requirements for water. Here a favorable tradeoff between ecological and human requirements for water is one that is amenable to negotiations between these two classes of users. An implicit assumption throughout this study is that ecological requirements for water are equivalent to instream flow needs. The following sections provide a brief overview of the literature relating to the development of relationships between reservoir storage volume and the resulting properties of both the human and ecological requirements for water.

\section{Literature Review}

[9] Reservoirs, dams, locks, weirs, and diversions are all operated to regulate the flow of rivers, and all such regulation schemes impose an artificial flow regime on aquatic ecosystems. It is now well understood that the ecological integrity of river systems depends upon their natural dynamic character, and as result, Poff et al. [1997] and many others argue that a natural flow paradigm offers a clear framework for managing river ecosystems.

[10] There is an extensive literature devoted to determining how much water a river needs to sustain a healthy and diverse aquatic ecosystem (see recent review by Tharme [2003]). Similarly, there are well-established approaches for determining how to operate single and multiple reservoir systems for the purpose of providing a reliable and resilient source of water to meet human requirements (see reviews by Wurbs 
[1993] and Labadie [2004] and texts by Votruba and Broža [1989], Revelle [1999], Nagy et al. [2002], and McMahon and Adeloye [2005]). In spite of the extensive literature relating to the impacts of dams on rivers, methods for determining instream flow requirements, and the operation of water supply reservoirs to satisfy human water requirements, there are surprisingly few studies that address all of these topics, simultaneously, which is the goal of this study.

\subsection{Review of Literature on Reservoir Design and Operations for Human Water Requirements}

[11] Most previous reservoir operations studies have focused on the allocation of human uses of water for water supply, hydropower, irrigation, recreation, and flood control. There are two general mathematical approaches to modeling the behavior of reservoir systems: (1) optimization and (2) simulation. Simulation approaches to reservoir operations and design have been in use for over a century [Rippl, 1883] and are now so well developed that numerous textbooks are devoted primarily to the simulation of reservoir systems [Votruba and Broža, 1989; Wurbs, 1996; Nagy et al., 2002; McMahon and Adeloye, 2005]. The U.S. Bureau of Reclamation maintains an inventory of generalized software packages for the simulation of reservoir and watershed systems (http://www.usbr.gov/pmts/rivers/hmi/index.html). There is also an abundant literature that focuses on the optimization of multiple and competing releases of water from reservoirs for human water uses (see reviews by Wurbs [1993] and Labadie [2004] and texts by Revelle [1999], Nagy et al. [2002], and McMahon and Adeloye [2005]).

\subsection{Review of Literature on Reservoir Operations for Instream Flow}

\subsubsection{Optimization Approaches}

[12] Of the hundreds of optimization-oriented reservoir operations studies reviewed by Wurbs [1993], Revelle [1999], Nagy et al. [2002], and Labadie [2004], we have identified a relatively small number of studies that focus on the optimal tradeoff among ecological and human flow needs [Sale et al., 1982; Cardwell et al., 1996; Flug et al., 2000; Jager and Rose, 2003; Chaves et al., 2003; Harman and Stewardson, 2005; Suen and Eheart, 2006]. Within the context of optimization approaches, other than the above cited studies, instream flow is normally considered as a hard, fixed constraint assuring that, say, some minimum level of streamflow is provided. Recent literature has emphasized that instream flow needs are far more complex than a fixed aquatic baseflow requirement [Richter et al., 1996, 1997]. As a result, there is now much greater attention being given to assessing the impact of reservoir operations on the downstream properties of instream flow.

[13] There is a general evolution in the application of mathematical methods to reservoir (and other) problems. Our experience is that simulation approaches are usually developed before optimization approaches, in part because optimization approaches to reservoir operations always contain a simulation model of the behavior of the reservoir, embedded within the optimization model. Thus before one can integrate social, political, economic, and other factors into the determination of optimal reservoir operations, it is first necessary to be able to simulate reservoir operations, in this case, corresponding to both the human and ecological requirements for water. Therefore, rather than describe in detail the few previous studies (cited above) that have developed optimization approaches to the problem of balancing human and ecological flow requirements, this study focuses instead on simulation approaches for evaluating the fundamental tradeoffs associated with this problem.

\subsubsection{Simulation Approaches}

[14] Surprisingly, none of the books dealing with the simulation of reservoir systems [Votruba and Broža, 1989; Wurbs, 1996; Nagy et al., 2002; McMahon and Adeloye, 2005] provides guidance on the allocation of water to meet both human and ecological requirements for water other than the prescription of a minimum flow standard. Palmer and Snyder [1985] were among the first researchers to simulate the general impacts of instream flow requirements on the overall performance of a water supply system. They show that instream flow requirements can decrease the performance of a water supply system in terms of its ability to meet human water needs, by an order of magnitude. Nearly a decade later, reservoir simulation studies began to appear that investigated the impact of various instream flow policies on the resulting ecological flow regime below dams for particular reservoir systems [Alves and Henriques, 1994; Hughes and Ziervogel, 1998; Benjamin and Van Kirk, 1999; Shiau and $W u, 2004 ;$ J.-T. Shiau and F.-C. Wu, Pareto-optimal solutions for environmental flow schemes incorporating the intra-annual and interannual variability of the natural flow regime, submitted to Water Resources Research, 2006, hereinafter referred to as Shiau and $\mathrm{Wu}$, submitted manuscript, 2006].

[15] Alves and Henriques [1994] compare numerous methods for computing instream flow requirements downstream from dams, all of which are improvements over the approach in use in Portugal at that time, which was to set a minimum ecological flow somewhere between $2.5 \%$ and $5 \%$ of the mean annual streamflow and to prohibit reservoir flow diversions when reservoir inflows drop below that minimum ecological flow.

[16] Most previous research on approaches for determining reservoir operating rules that ensure the protection of instream flow regimes originates in South Africa. Hughes et al. [1997] and Hughes and Ziervogel [1998] summarize the development of an instream flow model combined with a reservoir simulation model that together can evaluate a range of reservoir operating rules on characteristics of instream flow. Attempts to reproduce the natural flow regime are made by comparing the output from the reservoir simulation model to predetermined flow percentiles taken from daily flow duration curves constructed for each month. Their instream flow model accounts for the maintenance of low flows, peak flows, and the durations of those events in each month, in an effort to reproduce important properties of the natural flow regime. The operating rule built into their model compares the cumulative deficit in yields with predetermined values to determine when and how much to reduce the recommended instream flows. Hughes and Ziervogel [1998] develop a modeling system very similar to the modeling system introduced here; however, they have not considered the wide range of operating rules considered here, nor is their system based on a comprehensive and widely used water resource planning model as is the case here (WEAP).

[17] Wollmuth and Eheart [2000] evaluate the impact on instream flow resulting from five different transfer rules 


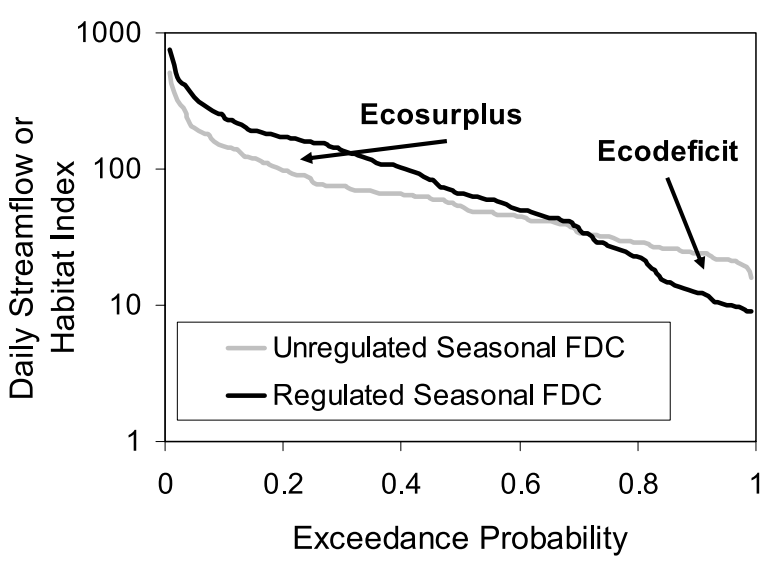

Figure 2. Definition of the ecodeficit and ecosurplus regions corresponding to areas between regulated and unregulated flow duration curves (FDCs).

from the free flowing river to an irrigation project: (1) no irrigation transfers allowed, (2) provide as much as irrigators need, whenever they wish (current practice in most eastern states), (3) provide as much as irrigators need, whenever they wish as long as downstream minimum flow standard is met, (4) transfer only a fixed volume of water per unit of irrigated land as long as the minimum downstream flow requirement is met, and (5) provide as much irrigation as farmer desires as long as the minimum downstream requirement is met and as long as a fraction of the inflow is set aside for release downstream. In general, they found that regulatory scenarios 1,2 , and 3 were not viable options and that of the two viable options, the fractional flow set aside scenario 5 is more effective and robust than the fixed volume permit scenario 4 . In a subsequent study, An et al. [2004] found that the any river withdrawal policy that ties allowable withdrawals to flows measured downstream of the reservoir can result in unstable feedback, which in turn can lead to severe variability of both the withdrawals and the resulting instream flows.

[18] Shiau and $W u$ [2004] and Benjamin and Van Kirk [1999] describe the use of the indicators of hydrologic alteration (IHA) and the range of variability approach (RVA) introduced by Richter et al. [1997] to evaluate the hydrologic impacts of flow regulation on specific dam systems. Shiau and $W u$ [2004] show that a reduction in dam diversions combined with a minimum flow requirement can alleviate some of the negative impacts associated with the altered flow regime. Similarly, Benjamin and Van Kirk [1999] describe the reservoir conditions and frequency with which instream flow requirements can and cannot be achieved.

[19] In spite of these efforts, little guidance exists on suitable reservoir operations policies for assuring adequate water for both human and instream flow requirements. The experiments reported below are an initial attempt to derive more generalized conclusions by examining the tradeoff between water supply yield and instream flow properties for a wide class of reservoir systems.

\section{Evaluating Reservoir Management Using the Ecodeficit}

[20] It is common practice to summarize the behavior of water supply yield by reporting only one or two summary statistics such as the mean annual yield and reliability. Summarizing instream flow properties is more complex because instream flows range over several orders of magnitude, making it necessary to examine their seasonal or monthly frequency, magnitude, and duration of occurrence. Tharme [2003] and Annear et al. [2004] review a wide variety of approaches for defining watershed-specific instream flow prescriptions. More recent instream flow methods are now based on the premise that departures from the natural flow regime can be expected to result in degradation in river health [Poff et al., 1997]. One of the most commonly used approaches for evaluating the degree of alteration of the hydrologic flow regime is the range of variability approach (RVA) [Richter et al., 1997], which involves defining instream flow goals based on up to 33 different hydrologic statistics. However, in order to construct relationships between storage, yield, and instream flow, a single, overall measure of instream flow protection is needed. We recognize that a single metric is not adequate to quantify the behavior of instream flows. Nonetheless, for this initial case study we introduce the metrics, ecodeficit and ecosurplus, which are based on a flow duration curve. The ecodeficit and ecosurplus can be computed over any time period of interest (month, season, or year) and reflect the overall loss or gain, respectively, in streamflow during that period that results from flow regulation.

[21] Flow duration curves are commonly used in a variety of instream flow assessment methods [Vogel and Fennessey, 1995; Annear et al., 2004; Acreman, 2005], because they provide a graphical illustration of the overall hydrologic state of a river system. A flow duration curve (FDC) is simply a plot of the ordered daily streamflow observations $\mathrm{Q}_{(\mathrm{i})}$ (where $i=1$ is the largest flow) as a function of their exceedance probability $p_{i}=i /(n+1)$, where $n$ is the number of days of flows and $i$ is the rank. Two different types of FDCs are possible: (1) period-of-record FDCs and (2) a median annual or seasonal FDC, representing the exceedance probability of daily flows in a median year or season [see Vogel and Fennessey, 1994]. In this study we employ median seasonal FDCs instead of median annual FDCs because annual FDCs mask the impact of seasonal variations in the flow regime. For example, a median summer FDC is constructed by developing $n$ summer FDCs corresponding to each of the $n$-years of flow records and then reporting the median of those FDCs. The resulting median summer FDC represents the exceedance probability of daily streamflow in a typical, or median, summer. In this study we divide the year into three seasons: spring (MarchJune), winter (November-February), and summer (JulyOctober). These periods were selected based on their biological and hydrological similarity for rivers in the northeastern United States.

[22] Figure 2 uses a shaded curve to illustrate the FDC for a river not subject to any withdrawals, and hence is said to be unregulated. The solid curve in Figure 2 represents a simulated FDC for the same river when subject to withdrawals. Both curves represent the cumulative probability distribution of instream flows. The area depicted in Figure 2 both below the unregulated FDC and above the regulated FDC is termed the ecodeficit. The ecodeficit area represents the net volume of water now unavailable to meet instream flow requirements due to the combined impact of the water 
withdrawals and the attenuation of inflows by the storage reservoir. Conversely, the area both above the unregulated FDC and below the regulated FDC is termed the ecosurplus. Despite the connotation associated with the term "ecosurplus," we note that any change in the natural flow regime, whether higher or lower, can impair ecological integrity, depending on the magnitude, timing, duration, and frequency of those deviations [Poff et al., 1997]. Ecosystems depend upon both high flows and low flows for optimal health. When calculated seasonally, we divide the seasonal ecodeficit by the mean seasonal inflow to the reservoir to quantify the fraction of streamflow no longer available to meet instream flow requirements during a particular season.

[23] The ecodeficit/ecosurplus provides a simplified representation of hydrologic impacts, as compared with the use of the more complex IHA and RVA hydrological approaches. The ecodeficit/ecosurplus concept is not limited to evaluation of streamflow regimes because it can also be applied to habitat duration curves [see Vogel and Fennessey, 1995]. While FDCs, and thus ecodeficits, can represent the historical frequency of streamflows during months, seasons, or years, they may be unable to capture the serial history of streamflow patterns and thus of the life history requirements of target species in a particular river system. Even though FDCs do not account for the timing or duration of particular flow events, the use of seasonal or monthly FDCs can capture some timing impacts. In addition, the ecodeficit defined in Figure 2 results in a graphical representation that provides an easily understood visualization of changes to flow conditions and therefore offers significant potential as a communication tool. Research is under way that evaluates the ability of monthly, seasonal, and annual ecodeficits to adequately characterize the impacts associated with flow regulation on the downstream flow regime. While use of monthly and/or seasonal ecodeficits enables an evaluation of some aspects of streamflow timing, research is needed to determine whether or not the ecodeficit can capture the life history breeding requirements of target species.

\section{Case Study Approach and Goals}

[24] Our primary goal is to evaluate the tradeoff between meeting instream flow and human requirements for water for water supply systems fed by a reservoir system. Another goal is to develop a methodology that can be used for evaluating the impact of alternative reservoir operating rules on the tradeoff between meeting ecological and human flow requirements.

[25] Simulation experiments are performed that result in relationships between reservoir storage volume $S$ and properties of both water supply yield $Y$ and instream flow $I$ for a variety of reservoir release operation rules. For a specific storage reservoir system, our simulation experiments deliver the maximum water supply yield without failure over the historical record subject to a range of reservoir release rules that capture different degrees of protection of the instream flow regime. Although these experiments only consider a single-purpose water supply reservoir, our experimental results should be applicable to any reservoir system that conserves water during wet periods for use during dry periods including other functions such as irrigation and hydropower.

[26] To enable our work to be general and to support followon studies, we adapt an existing water resource planning model to achieve our goals. Numerous different reservoir operating policies have been embedded into the generalized WEAP model [Yates et al., 2005a, 2005b] which is described below. Thus an important feature of this research is that it results in extensions to an existing water planning model that should enable future evaluations of the tradeoffs between ecological and human requirements for water. The following sections describe WEAP, the operating policies added to WEAP, and the results of our simulation experiments.

\subsection{The Water Evaluation and Planning Model (WEAP)}

[27] The water evaluation and planning (WEAP) model is a scenario-driven decision support system (DSS) designed to support water planning. WEAP operates on the basic principle of water balance accounting, where both engineered and biophysical components of a water system are represented to facilitate a multistakeholder water management dialogue on a broad range of topics including, among others, reservoir operations and ecosystem requirements on which this research is focused. The structure of the WEAP model is unique in that it integrates the physical hydrologic processes of a system with the management of institutions and infrastructure governing the allocation of water resources [Yates et al., 2005a, 2005b]. The model provides an ideal framework within which to evaluate the relationship between a reservoir's storage, yield, and instream flow requirements [Lévite et al., 2003; Yates et al., 2005b].

[28] The WEAP framework and data objects are graphically oriented, with the software built using the Delphi Studio ${ }^{\circledR}$ programming language (Borland Software Corporation), and also utilizing MapObjects ${ }^{\circledR}$ software libraries from the Environmental Systems Research Institute (ESRI). The framework allows for spatial referencing of watershed attributes (e.g., river and groundwater systems, demand sites, wastewater treatment plants, watershed and political boundaries, and river reach lengths) [Yates et al., 2005a, 2005b]. Here the data object framework in WEAP is used to describe a simple system containing one river with a reservoir and an instream flow requirement on the downstream river.

[29] Reservoirs in the WEAP DSS are considered demand sites (when filling) and can be configured to store water that becomes available either through the solution of a physical hydrology module or from a user-defined time series of inflows from upstream. A reservoir's operating rules in WEAP determine how much water is available in the current time step for release to satisfy downstream demands including, among others, instream flow requirements. Instream flow requirements in WEAP are used to represent established or new requirements for reservoir releases to the river. These data objects are assigned a priority and release value that must be maintained during a specified period.

[30] An application programming interface (API) functions in conjunction with WEAP, which allows the user to control WEAP data values directly using another program, programming language, or scripts. This feature is particularly useful in our evaluation of storage, yield, and resulting instream flow, because it enables repetitive simulations each with different input parameters.

\subsection{Simulation Experiments}

[31] Simulation experiments are performed using WEAP to explore the tradeoff between instream flow properties and reservoir yield $Y$ corresponding to a range of instream flow 
policies for a wide class of reservoir systems. To capture a wide range of reservoir yields, we consider yield ratios $Y / \mu$ in the range $[0,1]$, because it is impossible for a reservoir to deliver more than its mean annual inflow $\mu$. To capture the behavior of a wide class of reservoir systems, we consider reservoirs with storage ratios $S / \mu$ in the range [0, 3], where $S$ is storage capacity and again $\mu$ is the mean annual inflow to the reservoir. Larger storage ratios are generally needed as the yield ratio approaches unity and in regions with high streamflow variability. Vogel et al. [1999, Figure 9] and Graf [1999, Table 1, Figure 1] document that storage ratios in the range $[0,3]$ should capture the behavior of most reservoirs across the United States with values below 1 typical of temperate regions and values above 1 typical in the more arid regions of the United States. For a given river and reservoir release policy there is a unique relationship between the storage and yield ratio. The following simulation experiments explore the impact of the type of reservoir release policy on the behavior of the storage yield relationship and on the instream flow properties below a reservoir.

[32] Daily reservoir system simulations are implemented using WEAP over the 20-year period 1960-1979, using daily streamflows for the Green River at Williamstown, Massachusetts (U.S. Geological Survey gage 01333000) which has a drainage area of 42.6 square miles $\left(110 \mathrm{~km}^{2}\right)$. This streamflow record was used because it is a relatively unregulated gage and includes the drought of record for this region. A sequent peak algorithm is employed to determine the steady state water supply yield which can be delivered without failure over the 20-year period for all reservoir operating rules described below, over the range of storage ratios considered. The sequent peak algorithm is identical to the graphical mass curve approach introduced by Rippl [1883] and is the approach used to design most surface water supply reservoirs in the United States. The resulting reservoir yield is termed a "safe yield" because that is the standard parlance used in practice. The algorithm assumes that the reservoir starts full and requires that the storage reservoir must refill at some point after the worst drought on record. The resulting reliability associated with the reservoir yield and the instream flow are both $100 \%$ over the 20 -year historical simulation period. In practice, one may allow failures; however, to reduce the complexity of the problem and the number of degrees of freedom in this initial study, we only consider failure-free operations over the 20-year historical planning period. Although average annual yields are reported, we allow actual daily reservoir yields to vary seasonally based on average seasonal use factors for 42 surface-water-dominated drinking water reservoirs in Massachusetts [Waldron and Archfield, 2006].

\subsection{Reservoir Operations Policies}

[33] This study considers a wide range of alternative reservoir release rules that have been incorporated into WEAP to enable future extensions to this work. The instream flow releases and the human demands for water both operate as demands on the reservoir. Instream flow is defined as the streamflow release immediately downstream of the reservoir which may consist of either or both a required release intended for protection of the downstream flow regime as well as uncontrolled spills. A wide range of policies are considered in an effort to capture policies in common use as well as some promising policies suggested in the literature. The policies we consider do not necessarily represent policies that would protect the ecological integrity of downstream aquatic systems. We consider the following operating policies:

\subsubsection{No Instream Flow Releases}

[34] There are no instream flow releases but all human water demands are met. Instream flows occur only when the reservoir spills.

\subsubsection{Fraction of Inflow (FOI)}

[35] A fraction of the reservoir inflow is released as instream flow. In practice, one only has access to yesterday's reservoir inflow, and hence our model assumes reservoir inflow is yesterday's inflow.

\subsubsection{Fixed Minimum Release}

[36] This requires a fixed minimum instream flow release equal to the default summer aquatic base flow (ABF) defined by the U.S. Fish and Wildlife Service in the Interim Regional Policy for New England Stream Flow Recommendations as the August median daily streamflow, when data are available for its estimation [Lang, 1999]. For watersheds in New England over 50 square miles $\left(129.5 \mathrm{~km}^{2}\right.$ ), where site-specific data are not available, $\mathrm{ABF}=0.5$ cubic feet per second per square mile. We used this default $\mathrm{ABF}$ for illustrative purposes despite the fact that our watershed area was just below 50 square miles $\left(129.5 \mathrm{~km}^{2}\right)$. Here $\mathrm{ABF}=$ $21.3 \mathrm{cfs}=13.76 \mathrm{mgd}$, which corresponds to a daily flow which is exceeded $79 \%$ of the time in a median year. If the reservoir inflow is less than the instream release requirement, then only the reservoir inflow is released.

\subsubsection{Fixed Minimum Flow With Augmentation}

[37] This requires the ABF minimum instream flow release at all times, even when the reservoir inflow is less than the $\mathrm{ABF}$ flow requirement.

\subsubsection{Flow Components (FC)}

[38] This rule follows the fraction of inflow (FOI) release rule (see above), with one exception: It attempts to provide occasional high-flow releases for habitat improvement. Flows are considered to be a high flow if they fall above the 75 th percentile of all flows. After three high flow events have occurred in a season, no further high flow releases are required.

\subsubsection{Drought Management}

[39] A drought management policy can be implemented with any of the above instream flow policies. If reservoir drops into the buffer zone (below 50\% full), both yield and instream flow releases are reduced equally and proportionally. The lower the reservoir level falls, the greater the reduction. The reduction gradually increases from $0 \%$ to $35 \%$ as the reservoir level falls from $50 \%$ full to $0 \%$ full. The reservoir yield reported in this case is the "effective yield," which accounts for the reduction in yield due to drought management. In this initial study, drought management is only illustrated for the FOI policy.

\section{Results}

\subsection{Storage-Yield Relationship}

[40] Figure 3 illustrates storage yield curves corresponding to each of the instream flow release policies. As expected, all policies generally lead to lower yields than the "no instream release" policy. From Figure $3 \mathrm{a}$ it is evident that the type of operating rule has an enormous impact on the storage yield relationship for nearly all 
(a)

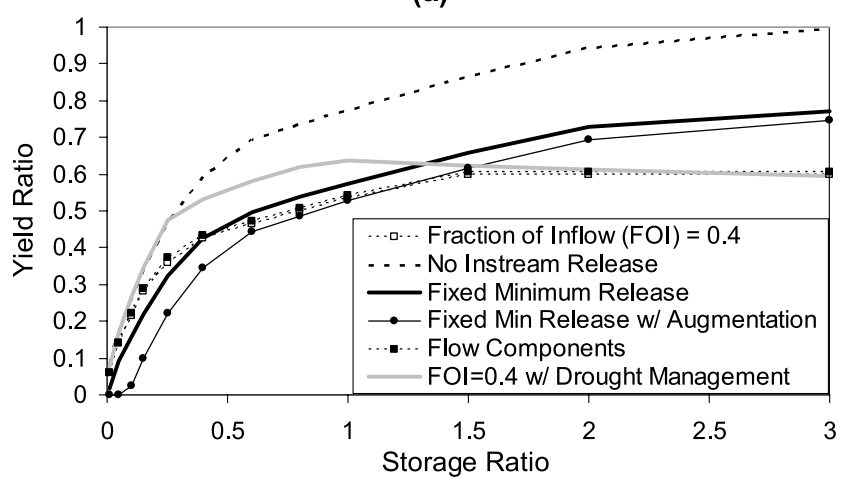

(b)

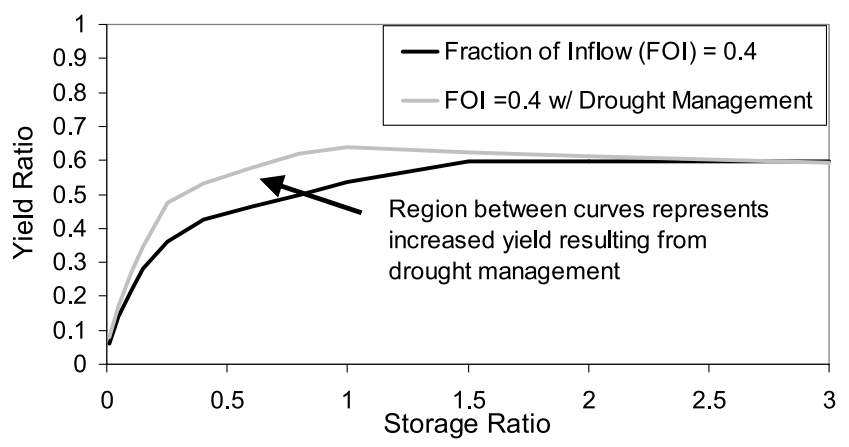

Figure 3. The storage yield relationship for various instream flow policies.

storage ratios. Naturally, the lowest reservoir yields result from the minimum flow with augmentation policy, because releases are required even when reservoir inflows are lower than the required release $(\mathrm{ABF})$.

[41] Of particular interest in Figure 3 are the results for the fraction of inflow policy $(\mathrm{FOI}=0.4)$ with drought management. The FOI policy combined with drought management lead to an almost identical storage yield relationship as for the case of no instream flow release, for all storage ratios below 0.3. Similar results are obtained when the flow components (FC) policy is combined with drought management. This implies that from the perspective of human water use requirements, there may be reservoir management policies that include drought management that can lead to human water yields commensurate with yields for systems with no instream flow requirements for small storage ratios.

[42] Of further interest is the shape of the storage yield curve when drought management is added to the FOI policy as highlighted in Figure 3b. Here yields actually reduce as the storage ratio increases above 1.0. How can reservoir yield decrease as reservoir storage increases? When drought management is implemented, the effective yield (after drought management) is reported in Figure 3. Apparently, for storage ratios above 1.0, the marginal increases in reservoir yield resulting from marginal increases in storage are less than the marginal decreases in reservoir yield resulting from marginal increases in drought management. Essentially the same result was obtained when drought management was combined with the FC policy. We con- clude that drought management will have its greatest impact for reservoir systems with small storage ratios.

[43] It is important to realize that drought management will always be an effective management strategy for reducing water use; however, Figure $3 \mathrm{~b}$ illustrates additional gains in overall reservoir yield that are above and beyond the magnitude of the reductions in demand. Another way to understand why average annual reservoir yields increase due to drought management is because drought management curtails water use during the driest periods (when storage is drawn down), enabling the storage reservoir to deliver reduced yields during the worst drought on record leading to a greater long-term average annual "safe" yield. This effect is most apparent for smaller storage ratios because such systems have the greatest marginal increase in yields for a given marginal increase in storage due to the "flattening" of the storage yield curve as storage ratios increase. The overall gains in net or effective yield due to drought management correspond to the region between the two storage yield curves illustrated in Figure $3 \mathrm{~b}$.

\subsection{Storage-Instream Flow Relationship}

[44] When plotting relations between storage and yield as in Figure 3, it is standard practice to report the mean annual yield, even though yields vary seasonally as in our experiments. There is no standard practice for plotting storageinstream flow relations and unlike water supply yield, instream flow varies by several orders of magnitudes during a typical year. Here again, instream flows represent the total reservoir releases made to the downstream river to maintain instream flow requirements. Because of the gross variations in instream flow in a typical year, it is more informative to examine the median instream flow rather than the mean instream flow. We normalize the median instream flow by dividing by the mean reservoir inflow $\mu$, which we term the median instream flow fraction. The median instream flow fraction represents the median daily instream flow as a fraction of the average inflow, so it represents the typical or median fraction of the total streamflow mass leaving the reservoir. Figure 4a reports the median instream flow fraction as a function of the storage ratio. Figure 4 a documents dramatic reductions in the median instream flow fraction as reservoir storage ratios increase from 0 to 0.2 , for all reservoir operating policies. Figure $4 \mathrm{~b}$ illustrates the relationship between the maximum of the three seasonal ecodeficits (reported as a fraction of the mean reservoir inflow) and the storage ratio. Instead of reporting the total ecodeficit, we report 1 - maximum[seasonal ecodeficit], because the largest seasonal ecodeficit should be indicative of the most significant ecological impacts. In the remainder of this paper, we refer to 1 - maximum[seasonal ecodeficit] as the ecoflow indicator. Note that ecosurplus values are mostly zero, and the nonzero values are very small compared with the ecodeficit values, and hence we do not report the ecosurplus values here.

[45] A comparison of Figures $4 \mathrm{a}$ and $4 \mathrm{~b}$ indicates that as the storage ratio increases, the decreases in the ecoflow indicator are generally similar to the decreases in the median instream flow fraction; however, the ecoflow indicator provides a much greater distinction between the impacts of the various policies than the median instream flow fraction. Figure $4 \mathrm{~b}$ illustrates that for storage ratios below 0.4 , the fixed minimum flow policies lead to much greater ecoflow values than any of the other policies, which is a 
(a)
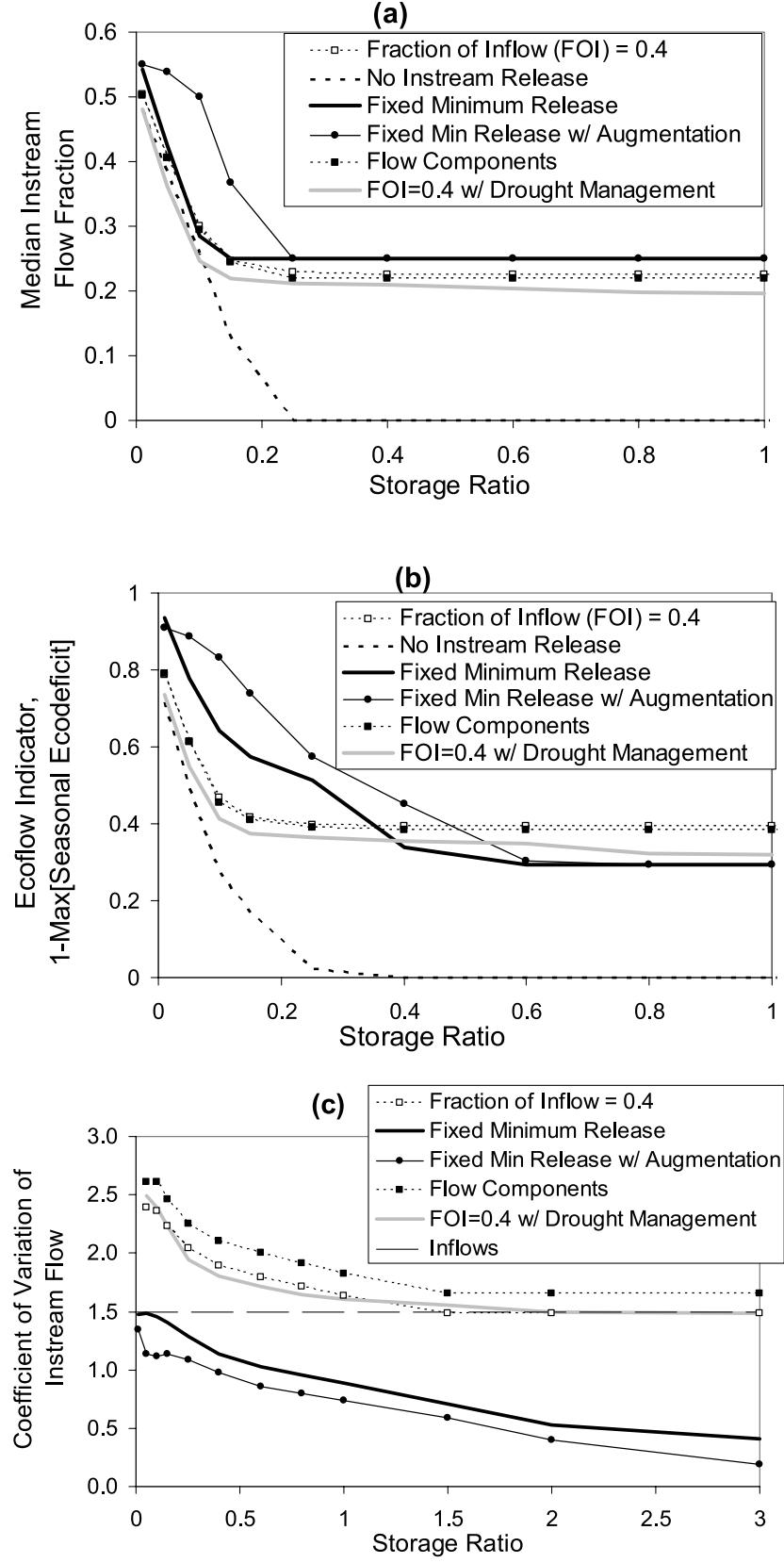

Figure 4. The storage-instream flow relationship for various operating policies.

different conclusion than would have been reached by viewing the median instream flow in Figure 4a. Figure 4a documents that with no instream flow policy, the river will be dry at least $50 \%$ of the time for storage ratios above 0.25 , and Figure $4 \mathrm{~b}$ documents that those dry conditions will continue for at least an entire season. We also observe from Figures $4 \mathrm{a}$ and $4 \mathrm{~b}$ that addition of drought management to the FOI policy always leads to slight decreases in the ecoflow indicator, in spite of the gains in yield reported earlier in Figure 3b. This is expected because the drought management policy reduces the reservoir releases in equal proportion to the reduction of yield.

[46] Figure 4c illustrates that the coefficient of variation of the daily instream flow steadily drops for all operating rules as the storage ratio increases. Figure $4 \mathrm{c}$ also highlights that use of a fixed minimum release strategy, with or without augmentation, generally leads to instream flows with lower variability than the reservoir inflows, whereas all other policies lead to increases in flow variability for storage ratios below 1.5. Figures $4 \mathrm{~b}$ and $4 \mathrm{c}$ illustrate that the two indicators ecoflow $=1-$ ecodeficit, and coefficient of variation, yield different conclusions, because for storage ratios below about 0.4 a fixed minimum release leads to higher ecoflows yet a lower coefficient of variation than the inflows. Poff and Allan [1995] found that differences in riverine fish communities in the upper Midwest could be explained fairly well by examining differences in the variability or stability in the daily flow regime. The results in Figure 4 are consistent with what was illustrated earlier in Figure 1; that is, it is more difficult to maintain instream flow properties for systems with large storage ratios than for systems with small storage ratios.

[47] Figure 5 illustrates box plots of the daily instream flows resulting from each of the instream flow policies for storage ratios of $0.1,0.4,1.0$, and 2.0. A box plot is a convenient way of graphically comparing the cumulative probability distribution of several sets of observations. Here we use the five-number summary, which consists of the 5th, 25th, 50th, 75th, and 95th percentiles. The box depicts the interquartile range of the observations (25th to 75th percentile), and the bold horizontal line represents the median (50th percentile).

[48] Comparing the box plots of the instream flows resulting from various operating policies with the box plot of the reservoir inflows shown on the left in each panel, one observes the gross differences in the probability distribution of instream flows that result from use of a minimum flow policy, with the greatest differences occurring for storage ratios above 0.1 . The FC and FOI policies lead to box plots with a shape very similar to the box plots of the reservoir inflows in all cases, and one can see that the increased variability in instream flows associated with these policies results from the occurrence of some instream flows that are smaller than the lowest recorded reservoir inflow. Figure 5 clearly illustrates the limitations of fixed minimum release policies for systems with large storage ratios, since the box plots of these policies for storage ratios $0.4,1.0$, and 2.0 are completely compressed. This demonstrates a loss of natural variability in flow associated with these policy types that would likely result in loss of river function and ecological intregrity if applied in the field.

\subsection{Tradeoff Between Instream Flow and Water Supply Yield}

[49] It is instructive to view the tradeoff that exists between providing water supply yield and preserving the natural flow regime for a particular reservoir system. The tradeoff between average annual yield and average annual instream flow is a zero sum tradeoff for all reservoir operating rules considered. In other words, every gallon of water released as yield is no longer available for instream flow. However, if one views other statistics of instream flow, such as the median instream flow fraction or the ecoflow indicator, a zero-sum tradeoff no longer results and it is this tradeoff that is of central interest in this study and is examined below.

[50] Figure 6 compares the ecoflow indicator and yield ratios for storage ratios of $0.1,0.4$, and 1.0. Again, as was demonstrated before in Figure $4 \mathrm{~b}$, it becomes increasingly 

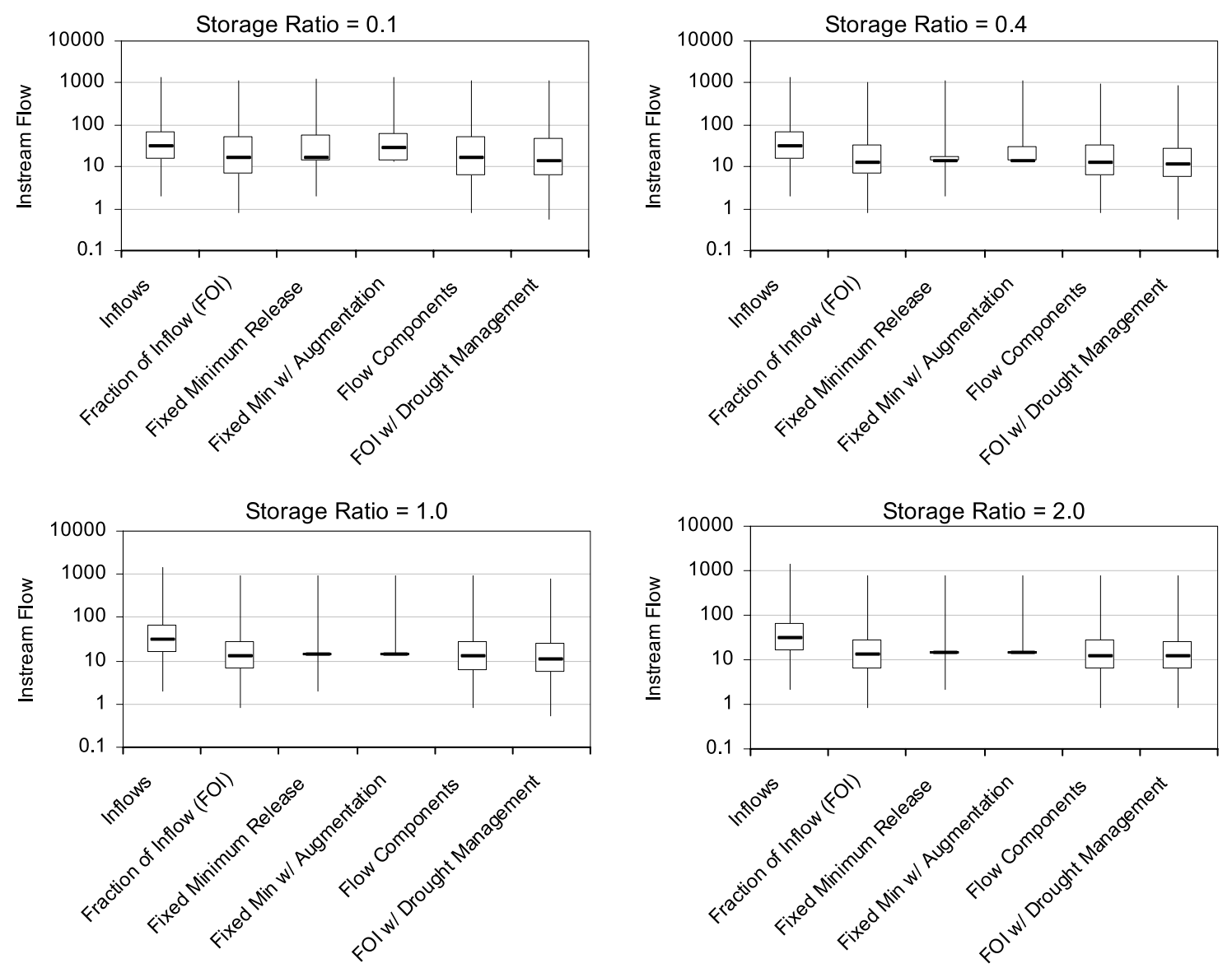

Figure 5. Box plots illustrating the distributions of the instream flows resulting from various reservoir operating rules. Also shown for comparison is the distribution of the reservoir inflows.

difficult to achieve high values of the ecoflow indicator, as the storage ratio increases. Consider a group of stakeholders attempting to reach consensus on a suitable reservoir operating policy to satisfy both ecoflow and yield objectives. An ideal policy would lead to values of both yield ratio and ecoflow, equal to unity in Figure 6, corresponding to a point in the upper right-hand corner. Such an ideal policy does not exist; however, it helps us visualize our aspirations. If we consider a storage ratio of 0.4 in Figure 6, any increase in ecoflow above and beyond the results for no instream flow release will lead to a decrease in yield. Of all the policies considered, the FOI $=0.4$ policy with drought management, shown with an open square, gives the greatest increase in ecoflow, for the least decrease in yield ratio, and hence it is probably more likely that a group of stakeholders could agree upon this policy over the other policies. Similar results are obtained for other storage ratios in Figure 6, and similar results were obtained for the FC policy but were not plotted here. In general, the greater the negative slope of the tradeoff between ecoflow and yield ratio in Figure 6, the more likely it is that stakeholders will be willing to decrease yield in order to increase ecoflows. Figure 6 documents that such negotiations are more likely for reservoir systems with small storage ratios, because such systems exhibit the largest negative sloped relations between ecoflow and yield ratio.

[51] Figure 6 illustrates that for all three storage ratios, drought management always leads to slight increases in the yield ratio, with only a slight reduction in the ecoflow indicator, so that drought management holds great promise for negotiating the tradeoff between ecoflow and yield. Another observation in Figure 6 is that the FOI policy (and by analogy the FC policy) provides a promising approach for spanning a wide range of tradeoffs between yield and instream flow, particularly for storage ratios greater than or equal to 0.4 . By adjusting the fraction of inflow parameter from 0.1 to 0.8 (which we term a policy parameter), the FOI and FC policies can be used to "adjust" the tradeoff between ecoflow and yield.

[52] Overall, our simulations reveal that for larger reservoir systems, with storage ratios above about 0.4 , both the FOI and FC policies as well as the drought management policy offer significant promise for aiding future negotiations between yield and instream flow with the FOI parameter used as a policy parameter. For smaller reservoir systems with storage ratios less than about 0.4 , a minimum release policy with or without augmentation, combined with drought management, offers promise for aiding negotiations. This is because for smaller reservoirs, higher flows are experienced by the downstream ecosystem due to frequent spill events allowing for protection of much of the natural flow regime without directed releases.

\section{Conclusions and Recommendations}

[53] This is one of the first studies that attempts to generalize our understanding of the storage-yield-instream 
- Fraction of Inflow (FOI=0.1-0.8)

$\times$ No Instream Release

Fixed Minimum Release

- Fixed Min Release w/ Augmentation

$\triangle$ Flow Components

FOl=0.4 w/Drought Management

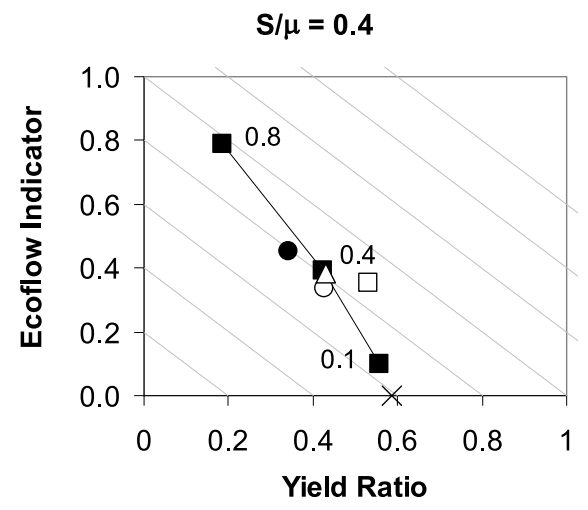

$S / \mu=0.1$
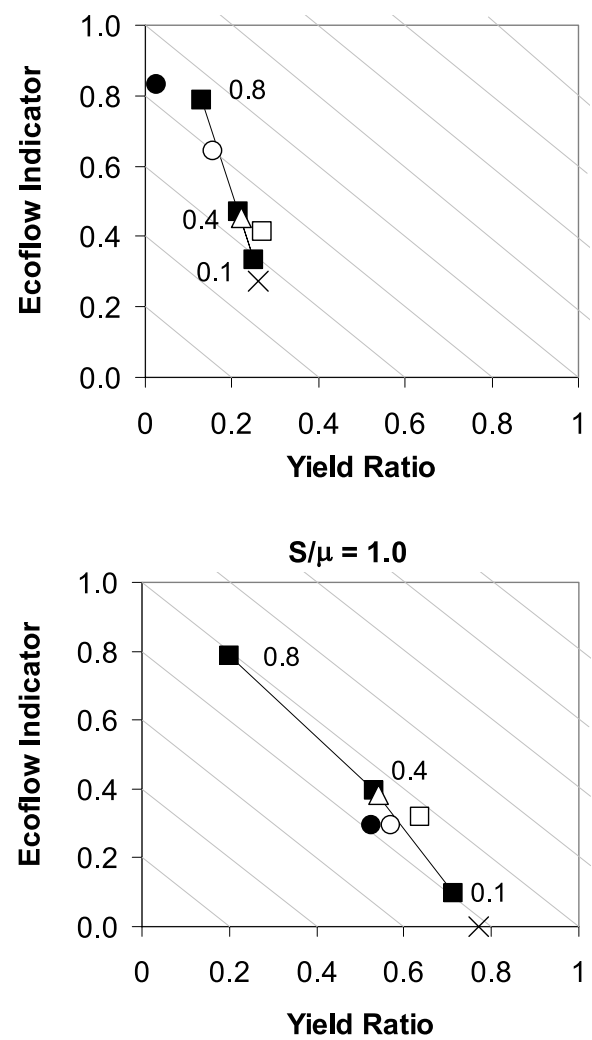

Figure 6. Illustration of the tradeoff between the ecoflow indicator (instream flow) and water supply yield. Increases in both yield ratio and the ecoflow indicator, 1-maximum[seasonal ecodeficit], correspond to improvements in yield and ecological flow regime, respectively.

flow relationship and to improve our understanding of the impact of reservoir operating policies on the tradeoff between properties of instream flow and water supply yield. A simple case study documents that the choice of a reservoir operating policy can have an enormous impact on the properties of both yield and instream flow and that different types of policies may be suited to different size reservoir systems (based on storage ratio). Overall, our simulations reveal that for larger reservoir systems (storage ratios above 0.4, approximately), both the FOI and FC policies in combination with drought management policy offer significant promise for aiding future negotiations between yield and instream flow with the FOI parameter used as a policy parameter. For smaller reservoir systems with storage ratios less than about 0.4 , a minimum release policy with or without augmentation, combined with drought management, may offer promise, though we caution that the modification to the low flow variability of the instream flows needs attention in these cases. Here drought management involves reductions in releases for both human and instream flows when reservoir storage levels are low.

[54] In general, drought management is shown to be an effective management strategy for reducing both human and instream flow water uses, and interestingly, for reservoir systems with storage ratios below unity we found additional gains in overall reservoir yield that exceed the magnitude of the reductions in demand. This extra benefit associated with drought management results from the fact that the demand curtailments in both human and instream flow releases occur at the time when the reservoir is drawn down, leading to overall increases in net or effective safe yield. Our findings also indicate that drought management is likely to have its greatest impact for reservoir systems with relatively small storage ratios, but that it is always a useful tool. Viewed only from the perspective of human water use requirements, the $\mathrm{FOI}$ and $\mathrm{FC}$ policies combined with drought management can lead to human water yields that are commensurate with yields for systems with no instream flow requirements for small storage ratios. Formalizing this type of drought management into actual reservoir operational guidelines is a challenge that appears to be worth pursuing.

[55] We document that it is much more difficult to maintain instream flows for systems with large storage ratios than for systems with small storage ratios. On the other hand, for a fixed storage ratio, we document the somewhat counterintuitive result that reservoir systems in temperate regions (low inflow variability) will generally have a lower fraction of water available for instream flow (relative to the mean annual flow) than similar systems in arid regions, which are subject to greater inflow variability.

[56] There are several promising natural extensions to this initial study. Much more rigorous evaluations are needed to determine the ability of the ecodeficit concept introduced here, to distinguish ecologically significant departures from the natural flow regime. Our initial attempt to evaluate the tradeoff between human and ecological flow needs was approached using a daily reservoir simulation model. A 
natural extension would be to reformulate the reservoir operations problem using an optimization framework with the goal of exploring the Pareto frontier that exists between human and ecological flow needs, analogous to the recent work by Homa et al. [2005], Suen and Eheart [2006], and Shiau and $\mathrm{Wu}$ (submitted manuscript, 2006). We envision the development of a Pareto frontier analogous to the curves in Figure 6 that exhibit the tradeoff between the two key objectives: (1) water supply yield and (2) instream flow. What distinguishes the curves shown in Figure 6 from a Pareto frontier is that each point on a Pareto frontier would be optimal in the context of a particular human and ecological flow objective. For example, such an approach could be used to determine the optimal degree of drought management combined with the optimal fractional inflow to release from the reservoir to meet a particular water supply reliability constraint while minimizing detrimental alteration of key aspects of the instream flow regime. In general, formulation of the problem as an optimization problem would enable us to optimize the various policy parameters associated with the reservoir operating policies which were recommended in this study. Such an approach would lead to Pareto frontiers that may facilitate negotiations between the various stakeholders involved.

[57] Acknowledgments. This research was supported by a grant from the U.S. Environmental Protection Agency's (EPA) Science to Achieve Results (STAR) program. Although the research described in this manuscript has been funded by the U.S. EPA (NCER grant X3832386), it has not been subjected to any EPA review and therefore does not necessarily reflect the views of the Agency, and no official endorsement should be inferred. The authors are indebted to Martha Fernandes, Chris Swartz, the associate editor, and two anonymous reviewers for their helpful suggestions on an early version of the manuscript.

\section{References}

Acreman, M. (2005), Linking science and decision-making: Features and experience from environmental river flow setting, Environ. Modell. Software, 20, 99-109.

Alves, M. H., and A. G. Henriques (1994), Instream flow determination for mitigating environmental impact on fluvial systems downstream dam and reservoirs, in Advances in Water Resources Technology and Management, edited by G. Tsakiris and M. A. Santos, pp. 351-358, A. A. Balkema, Brookfield, Vt.

An, H., J. W. Eheart, and R. D. Braatz (2004), Stability-oriented programs for regulating water withdrawals in riparian regions, Water Resour. Res., 40, W12301, doi:10.1029/2004WR003398.

Annear, T., et al. (2004), Instream Flows for Riverine Resource Stewardship, 267 pp., Instream Flow Counc., Cheyenne, Wyo.

Benjamin, L., and R. W. Van Kirk (1999), Assessing instream flows and reservoir operations on an eastern Idaho river, J. Am. Water Resour. Assoc., 35(4), 899-909.

Benke, A. C. (1990), A perspective on America's vanishing streams, $J . N$. Am. Benthol. Soc., 9, 77-88.

Cardwell, H., H. I. Jager, and M. J. Sale (1996), Designing instream flows to satisfy fish and human water needs, J. Water Resour. Plann. Manage., 122(5), 356-363.

Chaves, P. T., T. Kojiri, and Y. Yamashiki (2003), Optimization of storage reservoir considering water quantity and quality, Hydrol. Processes, 17(14), 2769-2793.

Collier, M., R. H. Webb, and J. C. Schmidt (1996), Dams and rivers: A primer on the downstream effects of dams, U.S. Geol. Surv. Circ., 1126, 94 pp.

Department of Water Affairs and Forestry (1997), White paper on a national water policy for South Africa, Pretoria.

Dynesius, M., and C. Nilsson (1994), Fragmentation and flow regulation of river systems in the northern third of the world, Science, 266, 753-762.

Flug, M., L. H. Seitz, and J. F. Scott (2000), Multicriteria decision analysis applied to Glen Canyon Dam, J. Water Resour. Plann. Manage., 126(5), $270-276$.

Graf, W. (1999), Dam nation: A geographic census of American dams and their large-scale hydrologic impacts, Water Resour. Res., 35(4), 1305-1311.
Harman, C., and M. Stewardson (2005), Optimizing dam release rules to meet environmental flow targets, River Res. Appl., 21, 113-129.

Homa, E., R. M. Vogel, M. P. Smith, C. D. Apse, A. Huber-Lee, and J. Sieber (2005), An optimization approach for balancing human and ecological flow needs, paper presented at the EWRI 2005 World Water and Environmental Resources Congress, Environ. and Water Resour. Inst., Anchorage, Alaska, 15-19 May.

Hughes, D. A., and G. Ziervogel (1998), The inclusion of operating rules in a daily reservoir simulation model to determine ecological reserve releases for river maintenance, Water SA, 24(4), 293-302.

Hughes, D. A., J. O'Keeffe, V. Smakhtin, and J. King (1997), Development of an operating rule model to simulate time series of reservoir releases for instream flow requirements, Water $S A, 23(1), 21-30$.

Jager, H. I., and K. A. Rose (2003), Designing optimal flow patterns for fall chinook salmon in a central valley, California, river, N. Am. J. Fish. Manage., 23, 1-21.

Labadie, J. W. (2004), Optimal operation of multireservoir systems: Stateof-the-art review, J. Water Resour. Plann. Manage., 130(2), 93-111.

Lang, V. (1999), Questions and answers on the New England Flow Policy, 9 pp., U.S. Fish and Wildlife Serv., Concord, N. H.

Lévite, H., H. Sally, and J. Cour (2003), Testing water demand management scenarios in a water-stressed basin in South Africa: Application of the WEAP model, Phys. Chem. Earth, 28, 779-786.

Magilligan, F. J., and K. H. Nislow (2005), Changes in hydrologic regime by dams, Geomorphology, 71(1-2), 61-78.

McMahon, T. A., and A. J. Adeloye (2005), Water Resources Yield, 234 pp., Water Resour. Publ., Highlands Ranch, Colo.

Nagy, I. V., K. Asante-Duah, and I. Zsuffa (2002), Hydrological Dimensioning and Operation of Reservoirs: Practical Design Concepts and Principles, 225 pp., Springer, New York.

Palmer, R. N., and R. M. Snyder (1985), Effects of instream flow requirements on water supply reliability, Water Resour. Res., 21(4), 439-446.

Poff, N. L., and J. D. Allan (1995), Functional organization of stream fish assemblages in relation to hydrological variability, Ecology, 76(2), 606627.

Poff, N. L., J. D. Allan, M. B. Bain, J. R. Karr, K. L. Prestegaard, B. Richter, R. Sparks, and J. Stromberg (1997), The natural flow regime: A paradigm for river conservation and restoration, BioScience, 47, $769-$ 784.

Postel, S. (1995), Where have all the rivers gone?, World Watch, 8(3), 919.

Postel, S., and B. Richter (2003) Rivers for Life: Managing Water for People and Nature, 253 pp., Island Press, Washington, D. C.

Revelle, C. S. (1999), Optimizing Reservoir Resources, 180 pp., John Wiley, Hoboken N. J.

Richter, B. D., J. V. Baumgartner, J. Powell, and D. P. Braun (1996), A method for assessing hydrologic alteration within ecosystems, Conserv. Biol., 10, 1163-1174.

Richter, B. D., J. V. Baumgartner, R. Wigington, and D. P. Braun (1997), How much water does a river need?, Freshwater Biol., 37, 231-249.

Rippl, W. (1883), The capacity of storage-reservoirs for water supply, Min. Proc. Inst. Civ. Eng., 71, 270-278.

Sale, M. J., E. D. Brill, Jr., and E. E. Herricks (1982), An approach to optimizing reservoir operation for downstream aquatic resources, Water Resour. Res., 18(4), 705-712.

Shiau, J.-T., and F.-C. Wu (2004), Assessment of hydrologic alterations caused by Chi-Chi diversion weir in Chou-Shui creek, Taiwan: Opportunities for restoring natural flow conditions, River Res. Appl., 20, 401-412.

Suen, J.-P., and J. W. Eheart (2006), Reservoir management to balance ecosystem and human needs: Incorporating the paradigm of the ecological flow regime, Water Resour. Res., 42(3), W03417, doi:10.1029/ 2005WR004314.

Tharme, R. E. (2003), A global perspective on environmental assessment: Emerging trends in the development and application of environmental flow methodologies for rivers, River Res. Appl., 19, 397-441.

Vogel, R. M., and N. M. Fennessey (1994), Flow duration curves: I. A new interpretation and confidence intervals, J. Water Resour. Plann. Manage., $120(4), 485-504$.

Vogel, R. M., and N. M. Fennessey (1995), Flow duration curves: II. A review of applications in water resources planning, Water Resour. Bull., $31,1029-1039$.

Vogel, R. M., and J. R. Stedinger (1987), Generalized reservoir storagereliability-yield relationships, J. Hydrol., 89, 303-327.

Vogel, R. M., M. Lane, R. S. Ravindiran, and P. Kirshen (1999), Storage reservoir behavior in the United States, J. Water Resour. Plann. Manage., $125(5), 245-254$. 
Votruba, L., and V. Broža (1989), Water Management in Reservoirs, Dev. Water Sci. Ser, vol. 33, 444 pp., Elsevier, New York.

Waldron, M. C., and S. A. Archfield (2006), Factors affecting firm yield and the estimation of firm yield for selected streamflow-dominated drinkingwater-supply reservoirs in Massachusetts, U.S. Geol. Surv. Sci. Invest. Rep., 2006-5044.

Wollmuth, J. C., and J. W. Eheart (2000), Surface water withdrawal allocation and trading systems for traditionally riparian areas, J. Am. Water Resour. Assoc., 36(2), 293-303.

Wurbs, R. A. (1993), Reservoir-system simulation and optimization models, J. Water Resour. Plann. Manage., 119(4), 455-472.

Wurbs, R. A. (1996), Modeling and Analysis of Reservoir System Operations, 356 pp., Prentice-Hall, Upper Saddle River, N. J.

Yates, D., J. Sieber, D. Purkey, and A. Huber-Lee (2005a), WEAP21: A demand-, priority-, and preference-driven water planning model: 1. Model characteristics, Water Int., 30, 487-500.
Yates, D., D. Purkey, J. Sieber, A. Huber-Lee, and H. Galbraith (2005b), WEAP21: A demand-, priority-, and preference-driven water planning model: 2. Aiding freshwater ecosystem service evaluation, Water Int., 30, $501-512$.

C. D. Apse, The Nature Conservancy, 108 Main Street, New Paltz, NY 12561, USA.

S. A. Archfield and R. M. Vogel, Department of Civil and Environmental Engineering, Tufts University, Medford, MA 02155, USA. (richard.vogel@tufts.edu)

A. Huber-Lee, International Food Policy Research Institute, $2033 \mathrm{~K}$ Street, NW, Washington, DC 20006, USA.

J. Sieber, The Stockholm Environment Institute, Tufts University, 11 Curtis Avenue, Somerville, MA 02144-1224, USA.

M. P. Smith, The Nature Conservancy, 11 Avenue De Lafayette, 5th Floor, Boston, MA 02111-1736, USA. 